\title{
Very high prevalence of vitamin D deficiency in South Asian adults (n 6433) in the UK Biobank: urgent action required
}

\section{Abstract}

Published studies have suggested a high prevalence of 25-hydroxyvitamin D (25OHD) deficiency in western dwelling South Asians, particularly in women. However, sample sizes have been relatively small with few men. Moreover, South Asians are vastly underrepresented in national dietary surveys and further research into $25(\mathrm{OH}) \mathrm{D}$ status is needed. The UK Biobank is a cohort of 500,000 individuals; $n 6433$ are of South Asian ethnicity and have baseline serum 25(OH)D data (2006-2010, aged 40-69 years). Blood draws were spread across the year. Of note, the $25(\mathrm{OH}) \mathrm{D}$ measurements were produced using the DiaSorin Liaison XL assay which underestimates $25(\mathrm{OH}) \mathrm{D}$ by $4 \%$ at $25 \mathrm{nmol} / \mathrm{L}$, but overestimates $25(\mathrm{OH}) \mathrm{D}$ by $5-10 \%$ at $\geq 40 \mathrm{nmol} / \mathrm{L}^{(1)}$. We used the commonly used cut-points of $<25 \mathrm{nmol} / \mathrm{L}$ (deficiency), $<50 \mathrm{nmol} / \mathrm{L}$ (insufficiency). In women ( $n$ 2927), median (IQR) was $24.3(20.5) \mathrm{nmol} / \mathrm{L}$ with $50.4 \%<25 \mathrm{nmol} / \mathrm{L}$, and $88.6 \%<50 \mathrm{nmol} / \mathrm{L}$. In men (n 3506), median (IQR) was $21.7(16.2)$ with $58.4 \%<25 \mathrm{nmol} / \mathrm{L}$ and $93.8 \%<50 \mathrm{nmol} / \mathrm{L}$. Of concern, $17.8 \%$ of women and $21.1 \%$ of men had $25(\mathrm{OH}) \mathrm{D}<15 \mathrm{nmol} / \mathrm{L}$. A Mann Whitney test showed that gender differences were statistically significant $(\mathrm{P}<0.0001)$. In terms of ethnic sub-groups, in the Bangladeshi group ( $n$ 207), median (IQR) was $26.1(14.3) \mathrm{nmol} / \mathrm{L}$ with $43.5 \%<25 \mathrm{nmol} / \mathrm{L}$ and $91.3 \%<50 \mathrm{nmol} / \mathrm{L}$. In the Indian group ( $n$ 4792), median (IQR) was $23.8(19.3)$ with $52.0 \%<25 \mathrm{nmol} / \mathrm{L}$ and $90.4 \%<50 \mathrm{nmol} / \mathrm{L}$. Finally, in the Pakistani group ( $n$ 1434) median (IQR) was $19.3(14.5)$ with $65.7 \%<25 \mathrm{nmol} / \mathrm{L}$ and $94.9 \%<50 \mathrm{nmol} / \mathrm{L}$. A Kruskal Wallis test showed that ethnic subgroup differences were statistically significant $(\mathrm{P}<0.0001)$. To the authors' knowledge, this is the largest analysis to date of $25(\mathrm{OH}) \mathrm{D}$ status in European dwelling South Asians. Deficiency of $25(\mathrm{OH}) \mathrm{D}$ was almost universal, with $50 \%$ or more not even reaching $25 \mathrm{nmol} / \mathrm{L}$. Of great concern, $20 \%$ of participants had levels $<15 \mathrm{nmol} / \mathrm{L}$ which, although not a widely used cut-off point, still represents severe deficiency and likely osteomalacia. Moreover, these results are most probably an underestimation of this societal challenge as the UK Biobank is likely to contain participants that are healthier and more educated than the general population. In conclusion, our analyses suggest the need for urgent public health interventions to prevent and treat vitamin D deficiency in UK South Asians. This research was conducted using the UK Biobank Resource under application number 15168.

\section{Conflict of Interest}

SL-N discloses that she is Research Director of D3-TEX limited which holds the UK and Gulf Corporation Council (GCC) patent for the use of UVB transparent clothing to prevent vitamin D deficiency. All other authors have no conflict of interest.

\section{Reference}

1. DEQAS (2017) DEQAS review 2016-2017. http://www.deqas.org/downloads/DEQAS\%20Review\%20October\%202017.pdf [accessed 27-6-19] 